\title{
Deferred Imitation and Social Communication in Speaking and Nonspeaking Children With Autism
}

\author{
Karin Strid, Mikael Heimann, Lars Smith, Christopher Gillberg and Tomas Tjus
}

\section{Linköping University Post Print}

\section{Tweet}

N.B.: When citing this work, cite the original article.

Original Publication:

Karin Strid, Mikael Heimann, Lars Smith, Christopher Gillberg and Tomas Tjus, Deferred Imitation and Social Communication in Speaking and Nonspeaking Children With Autism, 2013, Focus on Autism and other developmental disabilities, (28), 4, 230-240.

http://dx.doi.org/10.1177/1088357612468030

Copyright: SAGE Publications (UK and US)

http://www.uk.sagepub.com/home.nav

Postprint available at: Linköping University Electronic Press http://urn.kb.se/resolve?urn=urn:nbn:se:liu:diva-84324 


\section{Running head: DEFERRED IMITATION AND COMMUNICATION}

Deferred Imitation and Social Communication in Speaking and Non-speaking Children with Autism 


\begin{abstract}
The present study compares deferred imitation and early social communication skills among speaking and non-speaking children with autism and children with typical development. Overall, the children with autism showed a lower frequency on measures of both deferred imitation and social communication compared to typically developing children. Deferred imitation was observed at a significantly lower level among both the speaking and non-speaking groups of children with autism. However, when comparing the speaking autism group with the typical group many differences in observed social communication disappeared.

The study points to the importance of considering the child's verbal ability in autism research and indicates that specific difficulties in deferred imitation and in initiation of social communication are present in this group of children.
\end{abstract}




\section{Deferred Imitation and Social Communication in Speaking and Non-speaking Children with Autism}

Children with autism usually have severe impairments in social interaction and communicative ability. Communicative problems are evidenced in social attention and regulation problems, and about a quarter of the children with autism never develop spoken communicative language (Hus, Pickles, Cook, Risi, \& Lord, 2007). Joint attention is one of the prerequisites for the development of language, which is typically delayed in children with autism (e.g. Carpenter, Pennington, \& Rogers, 2002). Another early emerging ability, which has not yet been well investigated in children with autism, is deferred imitation, although this capacity is related to both language (Heimann et al., 2006; Rose, Feldman, \& Jankowski, 2009) and cognitive competence (Strid, Tjus, Smith, Meltzoff, \& Heimann, 2006) in typically developing children.

In the present, partly exploratory study, the main focus was to investigate deferred imitation and social communication in children with autism and children with typical development. The second aim was to investigate how these abilities differ between speaking and non-speaking children with autism.

\section{Deferred Imitation}

Deferred imitation is imitation of a previous seen action that is no longer accessible by working memory, that is, stored in long-term memory. This means that in order to be successful on a deferred imitation task the child need to form a representation of what he or she saw previously, store that representation in memory and use it at a later time point. Deferred imitation of novel activities on objects has been extensively studied among typically developing infants and has been suggested to tap early recall memory besides being a test of imitation (e.g. Barr, Dowden, \& Hayne, 1996; Heimann \& Meltzoff, 1996; Heimann \& 
Nilheim, 2004). It is a skill emerging between 6 and 9 months (Barr et al., 1996; Meltzoff, 1988), and studies have shown that the ability to imitate after a delay increases with mental age (Hayne, Boniface, \& Barr, 2000). A positive relation between deferred imitation observed at 9 months and communication measures at 14 months has been reported (Heimann et al., 2006). In a follow-up study when these children were four years old (Strid et al., 2006), deferred imitation and joint attention were found to predict later cognitive competence, i.e. children with low scores on deferred imitation and joint attention in infancy also had lower cognitive level later in childhood. Research has also shown a positive relation between deferred imitation at 12 months and receptive language at 36 months (Rose et al., 2009).

Only a few studies to date have explicitly investigated the role of deferred imitation in autism. The findings reported show that children with autism perform at a lower level as compared to matched controls (Dawson, Meltzoff, Osterling, \& Rinaldi, 1998; Whiten \& Brown, 1998). However, a study comparing both immediate and deferred imitation in children with autism (Rogers, Young, Cook, Giolzetti, \& Ozonoff, 2008) showed similar levels of difficulties on both tasks. If upheld, this finding suggests that the reduced performance on deferred imitation tasks reflect problems with imitation and not with longterm memory. Important connections between deferred imitation and growth of language ability have also been reported in children with autism (Munson, Faja, Meltzoff, Abbott, \& Dawson, 2008; Toth, Munson, Meltzoff, \& Dawson, 2006). These two studies show that children performing better on deferred imitation at 4 years acquired communication skills (both receptive and expressive skills) at a higher rate between 4 and 6 years.

\section{Social Communication}

Social communicative skills involve the ability to coordinate the attention between a social partner and a proximal object or event (Mundy \& Sigman, 2006). One aspect of social communication is the ability for triadic sharing of attention between a child, another person 
and an object or event (joint attention). Joint attention requires an understanding of other people as intentional agents (Tomasello, 1995) and provides a foundation for later communicative development (Baldwin, 1995). The relation between joint attention and language development has been well investigated (Bakeman \& Adamson, 1984; Carpenter, Nagell, \& Tomasello, 1998), and several studies have shown the predictive validity of these early nonverbal skills for later language acquisition (Brooks \& Meltzoff, 2005; Morales et al., 2000; Tomasello \& Farrar, 1986; Ulvund \& Smith, 1996). Another social communicative skill, which requires a child and another person to engage in joint focus on an object, is requesting (Mundy, Kasari, Sigman, \& Ruskin, 1995). This is a nonverbal social skill used to regulate another's behaviour, as when a child is using gestures when trying to get a toy that is out of reach. Social communication also includes social interaction, such as turn-taking, which can be both with and without objects (Heimann et al., 2006). In this early developing ability, two persons are in the focus of each others attention, or they share attention about an object.

The communicative problems in autism are rooted in deficits within these early, basic social communication functions (Dawson et al., 2004; Mundy, Sigman, \& Kasari, 1994). For example, joint attention is one of the earliest difficulties detected in autism (Charman, 2003), and it has been suggested that difficulties with joint attention reflect an inability to understand the basic foundations of communication (Sigman \& Kasari, 1995). Functionally, when there is a dearth of episodes of joint attention the child may have fewer opportunities to learn language, since such episodes help him/ her link words with the correct objects (Baldwin, 1995). Impairments in nonverbal requesting and social interaction (including turn-taking), have been demonstrated in children with autism, but they are less pronounced as compared to the problems related to joint attention (Carpenter et al., 2002; Mundy et al., 1994). 
The ability to use functional speech in autism has been related to the development of interaction skills, including joint attention (Pry, Petersen, \& Baghdadli, 2009). The study by Pry et al. showed that children with autism who developed from non-speaking by 5 years to speaking at 8 years were the ones with the highest interaction competence. Different aspects of social communication such as joint attention, requesting and social interaction, capture the ability and motivation to share experiences with others and to understand and respond to communicative intentions. These are all aspects that are of great importance for social and communicative development in childhood.

\section{Aims of the Study}

The present study focuses on how deferred imitation and social communication abilities relate to language use in speaking and non-speaking children with autism in comparison with typically developing children. We hypothesized that children with autism as a group would perform at a lower level regarding deferred imitation, joint attention, requesting and social interaction skills than typically developing children but that speaking children with autism would perform at a similar level regarding deferred imitation, joint attention, requesting and social interaction skills as typically developing children when matched for language age.

\section{Method}

\section{Participants}

Twenty children with autistic disorder according to DSM-IV criteria (APA, 1994) (18 boys and 2 girls, mean age $=66.8$ months $)$, and 22 typically developing children ( 12 boys and 10 girls, mean age $=34.7$ months) participated in the study. Chronological, vocabulary and mental ages for the groups are listed in Table 1. Nineteen of the children with autism were diagnosed by specialized neuropsychiatric teams (the Child Neuropsychiatry Clinic, Sahlgrenska University Hospital and the neuropsychiatric team, Kungälv Hospital). The 
neuropsychiatric work-up comprised clinically validated instruments, either the Diagnostic Interview for Social and Communication Disorders (DISCO) (Wing, Leekam, Libby, Gould, \& Larcombe, 2002) or the Autism Diagnostic Interview-Revised (ADI-R) (Lord, Rutter, \& Le Couteur, 1994). One child was diagnosed by a pediatrician, and no details of the clinical evaluation were available. For this child, the level of autistic behaviour was measured with the Childhood Autism Rating Scale (CARS) (Schopler, Reichler, \& Renner Rochen, 1988) in order to validate the diagnosis, and scores indicated mild-moderate autism. The typically developing children were recruited from day-care centres situated in central Göteborg with families predominantly of middle to high SES. Information about the study was given to parents through their child's day-care centre, and parents who were interested in participating contacted the department. The children were selected based on how well they were matched to children with autism for receptive vocabulary. For five children (four in the autism group and one in the typical group) receptive vocabulary was not available or possible to assess, therefore expressive vocabulary score was used instead. There was no significant difference in mental age between the groups. However, the children with autism had a significantly higher chronological age compared to the typically developing children (Table 1).

\section{<Table 1 here $>$}

The children with autism were divided into two groups, a speaking and a non-speaking group. A child was considered as non-speaking if he/she did not use language for communication during any of the observations including the free play with the parent, and if the parent indicated that this level of communication was typical for the child. This means that the child could use sounds other than words or simple single words, and still be in the non-speaking group. The definition was made according to the definition of phrase speech used in ADI-R; the spontaneous use of at least two words in combination, one of which must be a verb (Joseph, Tager-Flusberg, \& Lord, 2002). Seven children were considered "non- 
speaking", and 13 children were considered "speaking". The categorisation was made by one of the authors (K.S). A researcher not involved in the project categorised the speaking status of five (25\%) randomly selected children and 100\% agreement was obtained. The means of chronological age, mental age and vocabulary age of these two groups are presented in Table 1.

\section{Estimating vocabulary.}

Children with autism. The Peabody Picture Vocabulary Test (PPVT - third edition) (Dunn \& Dunn, 1997) and a Swedish version of the MacArthur Communicative Development Inventories (SECDI, Eriksson \& Berglund, 1999; Berglund \& Eriksson, 2000) were administered to all children. Due to the large heterogeneity in the group - language level ranging from non-verbal to well-spoken children - we used the most appropriate test to estimate language age in the children. The test was chosen according to a hierarchic procedure; the PPTV was administered to all children and used to estimate receptive vocabulary when considered reliable $(n=9)$. For 11 children, the PPTV was not appropriate or possible to use. The reasons were that the child refused to point at the pictures, did not understand the instructions or did not cooperate. The second test of choice was SECDI, which is a parent report that comes in two different versions. The first version measures receptive vocabulary and is appropriate for children between 8 and 16 months. This version of the SECDI was used to estimate receptive vocabulary for 7 children. One child had a receptive vocabulary age above 16 months and for this child we used the second version of the SECDI (appropriate for children between 16 and 28 months), which also includes expressive vocabulary. For the last 3 children in the autism group, the SECDI was not possible to use because of ceiling effects and instead the Kaufmann expressive vocabulary subscale (Kaufman \& Kaufman, 1983) was the source for estimating language age. 
Children with typical development. The PPVT was used to measure receptive vocabulary for 21 of the children with typical development. One child was assessed with the Kaufman because he did not cooperate on the PPVT and were above the ceiling on the SECDI.

\section{Estimating mental age.}

Children with autism. If possible, mental age estimation was based on tests used as part of the diagnostic work-up. This was true for 15 of the children where clinically valid test results from Griffiths (Ahlin-Åkerman \& Norberg, 1991; Griffiths, 1970) and WPPSI (Wechsler, 1999) could be used. However, for four children, the clinical test results were either not available $(n=2)$ or considered unreliable according to clinicians who had made the assessment $(\mathrm{n}=2)$ and the children's mental level was estimated by the research team using Raven's Coloured Matrices (Raven, 1976). For one child with missing clinical evaluation we were unsuccessful in administering Raven's matrices and this child is not included in the calculation of the mean mental age for the autism group.

Children with typical development. The children with typical development were assessed using the McCarthy Scales of Children's Abilities (McCarthy, 1972). This test yields a General Cognitive Index based on verbal, perceptual-performance, quantitative, and memory scores. The General Cognitive Index was used to calculate mental age of the participants in this group.

\section{Procedure}

All children visited the Department of Psychology, University of Gothenburg twice, with one or two days between the visits. Each visit lasted approximately $1-1 \frac{1}{2}$ hours and every child was accompanied by at least one parent. The parent decided if he or she wanted to stay in the observation room or watch the child through a one-way mirror. The child was 
observed in the same room and by the same experimenter on both occasions. During these two days of observation several different areas were investigated. In the present paper, only the Abridged version of the Early Social Communication Scales (ESCS) (Mundy, Hogan, \& Doehring, 1996), deferred imitation (Meltzoff, 1985; 1988) and language estimation is presented. The ESCS was the first observation on the second day for all children. The deferred imitation tasks were modelled on the first visit and the child's response was observed on the second visit. All language tests were carried out on the first visit.

The part of the visits for deferred imitation and the ESCS were videotaped for later scoring by two cameras placed in the corners of the room. In addition, an imitation procedure between the child and the experimenter and a 24-minute free play between the parent and child were also videotaped although the results are not presented here. However, we used this free play observation when deciding the speaking or non-speaking status of the child (see details above). The reason that these observations were videotaped is that they need to be scored from tapes. All families received a symbolic gift and a copy of parts of the videotaped observations.

\section{Deferred imitation.}

Five actions with objects were used to measure deferred imitation. The objects, which were replicas of the ones originally used by Meltzoff $(1985 ; 1988)$ with typically developing infants, are described in Table 2. During visit one, the experimenter and the child sat at a table and the experimenter showed an action on each object three times in succession. The “observation-only-design” developed by Meltzoff (1995) was used. This means that during each presentation the child was not allowed to handle the objects, making sure that the child did not develop any motoric experience of the action. A delay was then imposed until the child came for his or her second visit approximately 2 days later $(\mathrm{M}=50.6$ hours, $\mathrm{SD}=8.55)$. 
The experimenter then put the object in front of the child and a 20 -second response time was allowed after the child had touched the object.

\section{$<$ Table 2 here $>$}

For three of the objects (i.e. the conventional tasks) we used the same scoring criteria as in the original studies (Table 2). For two objects (i.e. the non-conventional tasks) the demonstration and scoring were slightly changed so that the actions depicted required nonconventional responses. First, a pen was used, instead of a finger, to press the button on the box. Second, the elbow was used instead of the hand to press down the rectangle on the hinge. This modification was made to ensure that the children were imitating the actions, and not only reaching for the goal (Williams, Whiten, \& Singh, 2004). This means that for the three conventional tasks, the easiest or most obvious way to reach the goal is by imitating the previous seen action. However, for the two non-conventional tasks, the goal can be reached more easily by changing the action (i.e. using a finger to press the button on the box and to use the hand to press down the rectangle).

Two of the authors (K.S. and M.H.) coded all deferred imitation tasks (see Table 2 for scoring criteria). The isolated response period was used for the coding, and one of the coders (M.H.) had not participated in the actual data collection. Observer agreement across K.S. and M.H. was assessed by Cohen's kappa $(\kappa=.89)$.

\section{Social communication.}

In order to capture nonverbal joint attention, requesting and social interaction behaviours, the ESCS (Mundy, Hogan, \& Doehring, 1996) was administered at the second visit. The ESCS is a structured play situation designed to capture joint attention, behavioural requests and social interaction behaviours. For each area, the child can either initiate an action or respond to a behaviour initiated by the experimenter. The child and the experimenter sit at a table where some toys are visible for the child and others are on the floor behind the 
experimenter. The toys are designed to encourage social interaction between the two persons and during the testing the experimenter presents three wind-up toys, three mechanical toys, opportunities to play turn-taking games with a ball and a car, opportunities to play social games with a comb, hat and glasses as well as tickle games. In addition, posters are placed on the walls, two on each side and one behind the child and the child is encouraged to look at the posters after the experimenter has said the child's name and pointed at them. A similar trial is conducted with a picture book.

Initiating Joint Attention (IJA) includes both low-level and high-level behaviour. Lowlevel behaviours are scored when the child makes eye contact with the experimenter while touching a toy or is alternating eye contact between an active toy and the experimenter. Highlevel behaviours are scored when the child points at a toy before the experimenter point or shows a toy to the experimenter. The total frequency of high and low behaviours is reported. Responding to Joint Attention (RJA) measures how many times the child follows the direction of the experimenter's pointing. Each child gets up to 12 opportunities to follow pointing (pointing to pictures in a book or to posters on the wall), The exact number depends on the child's cooperation, thus a ratio score was calculated; i.e. the number of looks divided by the number of opportunities.

Initiating Object Request (IOR) includes eye contact with the experimenter when an active toy has stopped or disappeared. Other behaviours scored within this category are reaching for a toy, giving a toy to the experimenter and pointing for request. Responding to Object Request (ROR) is scored when the child gives a toy to the experimenter after a request. For both IOR and ROR, the total frequency of behaviours was recorded. Initiating Social Interaction (ISI) includes turn taking and teasing behaviour on the child's part. Turn taking is scored when the child initiates a turn taking sequence. The child is given two different toys (a car and a ball) and is encouraged with gestures to roll the toy the 
experimenter. Responding to Social Interaction (RSI) is scored when the child makes eye contact with the experimenter, bangs at the table or vocalizes after being tickled, maintains turn taking (either with the car or the ball after turn taking has been initiated by the child or experimenter) or responds to an invitation: The child is invited to play with a hat, a comb and glasses, which means that the experimenter initiate a play and says "now it is your turn". For both ISI and RSI, the total frequency of these behaviours was scored.

A research assistant coded all ESCS videos using the observation program from Noldus (Observer). The videos showed the child and the experimenter as well as the table between them. The observations were coded following the guidelines from the ESCS manual (Mundy, Hogan, \& Doehring, 1996). One of the authors (K.S.) coded 10\% of the observations selected on a random basis, revealing an agreement of kappa.76 and an intraclass correlation of $.99(p$ $<.001)$

\section{Statistical Analysis}

Non-parametric analyses (Mann-Whitney U-test) were used for all group comparisons.

\section{Ethics}

The study was approved by the ethical committee at University of Gothenburg (Ö 55502).

\section{Results}

\section{Deferred Imitation}

Overall, children with autism performed on a significantly lower level on the deferred imitation tasks as compared to the typical group (Table 3). This was also evident when comparing the non-speaking and speaking subgroups with the typical group. In contrast, separate analyses of conventional and non-conventional tasks showed similar group 
differences for the conventional tasks only. No significant group differences were found for the non-conventional deferred imitation tasks.

\section{$<$ Table 3 here $>$}

\section{Social Communication}

As shown in Table 4, the children with autism had significantly lower means on initiating and responding to joint attention and social interactions, as well as initiating behavioral requests. There was not a difference in responding to requesting (ROR) when compared to the typical group.

\section{$<$ Table 4 here $>$}

When the group of speaking children with autism was compared to the typical group, the groups performed at the same level on all measures except initiating joint attention (IJA) and initiating object requesting (IOR) (see Table 4). Comparing the non-speaking children with autism with the typical group, the autism group performed significantly lower on all variables.

\section{Gender}

Because the typical group and the autism group were not matched on gender, a separate analysis was conducted for boys only. The comparison between the boys with autism $(\mathrm{n}=18)$ and the boys with typical development $(\mathrm{n}=12)$ on social communication revealed a similar result as for the total group comparison, except for responding to joint attention (RJA) and responding to social interaction (RSI), which no longer reached the level of significance. This means that the boys with autism and the boys with typical development differed on all initiating, but none of the responding, variables. When analysing deferred imitation between boys only, identical results as for the total group comparison were obtained. 


\section{Discussion}

The present study investigated deferred imitation and social communication among speaking and non-speaking children with autism in comparison with typically developing children. Deferred imitation, initiating joint attention and initiating object requesting were observed at a lower level in speaking children with autism as compared to a languagematched comparison group of typically developing children matched for receptive vocabulary. In addition, responding to joint attention, responding to object requesting and responding as well as initiating social interaction were affected among the non-speaking children with autism.

\section{Deferred Imitation}

Few studies have investigated deferred imitation in relation to language competence in children with autism. The present results revealed that the children with autism performed lower on the deferred imitation task regardless of their ability to use spoken language or not. This is in contrast to earlier results reporting a connection between deferred imitation and language acquisition in autism (Munson et al., 2008; Toth et al., 2006). The present study used both conventional and non-conventional deferred imitation tasks. While the conventional tasks differed between the groups, no group difference was found on the non-conventional tasks. This could be due to low statistical power, since only two non-conventional tasks were included in the study. Another, more speculative, interpretation is that children with autism, in contrast to typical children, may fail to see any difference between non-conventional and conventional tasks, that is, they treat all tasks as unique actions without relying on previous experience. In this case, the typical children would show a disadvantage in the nonconventional tasks while the children with autism, by failing to recognise the odd behaviour in the non-conventional tasks, would treat both tasks in a similar fashion. This means that both groups would have similar problem on the non-conventional tasks but only the children 
with autism would have the same problem on the conventional tasks. This possibility needs further investigation using a more varied set of tasks and larger groups of children, but if this holds it will give us a deeper understanding about the imitation deficit seen in autism. Imitation of a non-conventional tasks show that the child is not only imitating the goal of the action, but rather the action itself. Previous research on children with autism (Charman \& Baron-Cohen, 1994) show that imitation of "novel actions" (i.e. strange actions that could be compared to our non-conventional actions) was difficult compared other action imitation tasks. However 12 out of 20 children with autism (mean verbal MA = 46 months) imitated the novel action and the task was equally difficult for children with developmental delays.

It is possible that lower performance on the total deferred imitation score in the autism group to some extent depends on an "imitation deficit" and not a general memory problem, although views differ regarding if, or to what degree, such a deficit exists (e.g., Heimann, Ullstadius, Dahlgren, \& Gillberg, 1992; Nadel, 2002; Smith \& Bryson, 1994; Williams et al., 2004). Previous research suggests that imitation of actions on objects (as in the deferred imitation tasks employed in this study) is less impaired in this group as compared to imitation of body movements (Stone, Ousley, \& Littleford, 1997) and role reversal imitation (Carpenter, Tomasello, \& Striano, 2005). Additional observations also indicate that problems with imitation are more profound in younger children with autism (Charman et al., 1997; Gopnik, Capps, \& Meltzoff, 2000), suggesting that imitation is not an absolute deficit in children with autism, and more depending on developmental level. In this study, being able to use spoken language did not help the children with autism to perform better on the deferred imitation tasks, even if the actions being imitated were simple actions on objects. Thus, deferred imitation might be especially demanding for children with autism. However, recent findings by Rogers et al. (2008) suggest that children with autism do not have more problems with deferred imitation than with other imitation tasks, which raises the question if the 
difficulties seen in deferred imitation tasks should be interpreted as imitation or memory deficits. These seemingly contradictory findings warrant future studies before we can conclude that there is a specific deficit in deferred imitation in children with autism.

\section{Social Communication}

Our findings replicate those of earlier studies (e.g., Charman, 2003; Mundy et al., 1994) demonstrating that problems with initiating joint attention are a robust finding among all children with autism, regardless of whether they are able to use spoken language or not. In addition, this also held for initiating object requesting. For responding to joint attention, requesting and social interaction as well as initiating social interaction, the performance of children with autism increased with the child's language ability. When comparing the nonspeaking autism group and the typical group, the children with autism performed at a lower level on all social communication variables measured in this study.

Joint attention depends more on social motivation and sharing experiences as compared to other communicative gestures. Sharing experiences with others involves a sharing of positive affect in typically developing children, but this may not be the case among children with autism (Kasari, Sigman, Mundy, \& Yirmiya, 1990). This probably makes joint attention more socially rewarding for typically developing children and could explain why children with autism are less motivated to engage in joint attention (Mundy \& Sigman, 2006). Joint attention also involves a change of own and others' minds, something that are especially difficult for children with autism to understand. Other social communicative gestures, such as requesting, are followed by a visible change in own or other people's behaviour (e.g., they give you a toy) (Gergely, 2004; Mundy et al., 1996) and might therefore be easier to understand and produce. In this study both initiating joint attention and initiating object requesting were difficult for all children with autism, whereas responding to joint attention was without any problems for the group of speaking children. This suggests that initiating and 
responding to joint attention relies on different abilities and that they should be investigated separately in autism research. Joint attention intervention for children with autism has been used with positive results (e.g. Kaale, Smith \& Sponheim, 2012). Kaale et al. randomly selected pre-school children with autism to an eight week joint attention intervention or to an ordinary pre-school program. The children in the joint attention intervention group significantly increased their joint attention skills in play with their teachers and also showed more joint engagements in play with their mothers. Results showing how difficulties with joint attention differ among individual children with autism could be used to develop more tailored interventions. The fact that the children with autism have difficulties to initiate joint attention could be addressed by increasing their motivation for communication by exposing them to fun and challenging language material. An example of this is using computers with challenging multimedia material resulting in more relevant and engaging communication with their teachers (Tjus, Heimann \& Nelson, 2001). Another strategy that could be explored is to

use imitation as an intervention strategy that has been found to be especially effective for nonspeaking children with autism, the group where initiating joint attention is a core problem (Heimann, Laberg, \& Nordøen, 2006).

\section{Individual Differences}

The present study highlights the importance of considering individual differences within the autism diagnosis spectrum (Mundy \& Sigman, 2006). Whereas the non-speaking children with autism evidenced reduced performance on all social communicative measures plus deferred imitation, the speaking children with autism displayed a pattern that was more similar to that observed among the typical group. In this study there were notable individual differences within the autism group on social abilities, but more general difficulties in deferred imitation, which indicate difficulties with recall memory and/or imitation tasks. It is important to note that the children with autism were older compared to the typically 
developing children, which means that they performed on a lower level than what was expected from their chronological age. This suggests that prototypic deficits in autism may not be absolute, but rather be related to the developmental level of the child (e.g. Mundy et al., 1994). The present results also have methodological implications, suggesting that the developmental level of the child and the heterogeneity of the group are important factors to consider in research on autism.

All participating children performed at a similar level on responding to object requesting. In the ESCS procedure (Mundy et al., 1996), a child may either respond to a gestural command (an open palm) or to a verbal command ("give it to me"), but these responses were not scored separately in the present study. Thus, if the child did not respond to the non-verbal command, the experimenter would give the child a verbal command, which means that the child did not need to understand communicative gestures in order to respond; the child just needed to understand and follow a command. This might explain the similar performance by children with autism and children with typical development on this task, since the task of interpreting an open hand as a command was absent in the task.

\section{Strength and Limitations}

The present study has two main strengths. First, it indicates that speaking and nonspeaking children with autism show a different pattern of difficulties within the area of social communication but more similar problems with deferred imitation. This shows the importance of considering individual differences in all autism research. Another strength is that the study included both conventional and non-conventional tasks of deferred imitation. It should be expected that children with autism would be less affected by the non-conventional actions in contrast to typical children. That is, the performance on non-conventional tasks should be more similar between the groups compared to performance on conventional tasks. This was also the result. It is important to note that the differences in performance on conventional and 
non-conventional tasks need to be replicated with larger groups and more items. However, by a detailed investigation of deferred imitation, the present study adds to our understanding of the nature of the imitation deficit in autism.

Research highlighting the heterogeneity among children with autism helps us to understand which areas of difficulties that needs to be targeted in intervention promoting language development. Our data suggest that the pattern of difficulties within the area of social communication differ among individual children with autism depending on their vocabulary development. One aspect that was difficult for all children with autism was initiating joint attention. This kind of knowledge will be helpful in creating more effective interventions. A more detailed understanding of how different communicative and imitation skills manifests in individual children are also important in understanding the unique challenges in children with autism.

Some important limitations of the present study need to be pointed out. First, the number of boys and girls in the autism group differed (18 boys, 2 girls), as compared to the group of typically developing children (12 boys, 10 girls). Analyses including only boys revealed a similar pattern of result as observed for the total group, except for responding to social interaction and responding to joint attention. The difference in the number of boys and girls in the two groups is important since one would expect that typically developing girls around 3 years of age have developed better language skills than boys at the same age (Bornstein, Hahn, \& Haynes, 2004). However, by matching the groups on language age, we tried to minimize this discrepancy as much as possible. A second limitation concerns the use of ESCS with children at different language levels. Some of the children with typical development and some of the speaking children with autism were above the chronological age recommended by the ESCS manual. This could have affected the results since these children might reduce their gestural communication and rely more on verbal language for social 
communication. However, it is unlikely that this was the case for the children with autism, since the speaking children had higher scores on all social communication measures compared to the non-speaking children.

\section{Conclusion}

The present study revealed that, for children with autism, most social communicative abilities depend on the child's ability to use spoken language, and that difficulties within these areas are not present to the same extent in all children with autism. It also revealed that deferred imitation in autism did not improve for speaking children as compared to children unable to use spoken language for communication purposes. Children with no or very limited speech tend to show impairments that are not observed among speaking children. This suggests that deferred imitation could be used as an additional measure when evaluating or assessing social and linguistic development in autism. A further exploration of individual differences in autism will not only help us identify important subgroups, but may also lead to better predictions of outcome and more effective intervention strategies. 


\section{References}

Ahlin-Åkerman, B., \& Norberg, L. (1991). Griffiths utvecklingsskalor. Göteborg: Psykologiförlaget (in Swedish).

APA. (1994). American Psychiatry Association. Diagnostic and statistical manual (4th ed.). Washington, DC: Author.

Bakeman, A., \& Adamson, L. B. (1984). Coordinating attention to people and objects in mother-infant and peer-infant interaction. Child Development, 55(4), 1278-1289.

Baldwin, D. A. (1995). Understanding the link between joint attention and language. In C. Moore \& P. J. Dunham (Eds.), Joint attention: Its origins and role in development (pp. 131-158). Hillsdale, NJ: Lawrence Erlbaum Associates.

Barr, R., Dowden, A., \& Hayne, H. (1996). Developmental changes in deferred imitation by 6- to 24-month-old infants. Infant Behavior and Development, 19(2), 159-170.

Berglund, E., \& Eriksson, M. (2000). Communicative development in Swedish children 16-28 months old: The Swedish early communicative development inventory - words and sentences. Scandinavian Journal of Psychology, 41(2), 133-144.

Bornstein, M. H., Hahn, C-S., \& Haynes, O. M. (2004). Specific and general language performance across early childhood: Stability and gender considerations. First Language, 24(3), 267-304.

Brooks, R., \& Meltzoff, A. N. (2005). The development of gaze following and its relation to language. Developmental Science, 8(6), 535-543.

Carpenter, M., Nagell, K., \& Tomasello, M. (1998). Social cognition, joint attention, and communicative competence from 9 to 15 months of age. Monographs of the Society for Research in Child Development, 63(4). 
Carpenter, M., Pennington, B. F., \& Rogers, S. J. (2002). Interrelations among socialcognitive skills in young children with autism. Journal of Autism and Developmental Disorders, 32(2), 91-106.

Carpenter, M., Tomasello, M., \& Striano, T. (2005). Role reversal imitation and language in typically developing infants and children with autism. Infancy, 8(3), 253-278.

Charman, T. (2003). Why is joint attention a pivotal skill in autism? Philosophical Transactions of the Royal Society B, 358(1430), 315-324.

Charman, T. \& Baron-Cohen, S. (1994). Another look at imitation in autism. Development and Psychopathology, 6, 403-413.

Charman, T., Swettenham, J., Baron-Cohen, S., Cox, A., Baird, G., \& Drew, A. (1997). Infants with autism: An investigation of empathy, pretend play, joint attention, and imitation. Developmental Psychology, 33(5), 781-789.

Dawson, G., Meltzoff, A. N., Osterling, J., \& Rinaldi, J. (1998). Neuropsychological correlates of early symptoms of autism. Child Development, 69(5), 1276-1285.

Dawson, G., Toth, K., Abbott, R., Osterling, J., Munson, J., Estes, A., \& Liaw, J. (2004). Early social attention impairments in autism: Social orienting, joint attention, and attention to distress. Developmental Psychology, 40(2), 271-283.

Dunn, (Loyd)., \& Dunn, (Leota). (1997). Peabody picture vocabulary test: Third edition. Circle Pines, MN: American Guidance Service.

Eriksson, M., \& Berglund, E. (1999). Swedish early communicative development inventory words and gestures. First Language, 19(55), 55-90.

Gergely, G. (2004). The development of understanding self and agency. In U. Goswami (Ed.), Blackwell handbook of childhood cognitive development (pp. 26-46). Oxford: Blackwell Publishing. 
Gopnik, A., Capps, L., \& Meltzoff, A. N. (2000). Early theories of mind: What the theory theory can tell us about autism. In S. Baron-Cohen \& H. Tager-Flusberg \& D. J. Cohen (Eds.), Understanding other minds: Perspectives from developmental cognitive neuroscience (pp. 50-72). Oxford: Oxford University Press.

Griffiths, R. (1970). The abilities of young children. A study in mental measurement. London: University of London Press.

Hayne, H., Boniface, J., \& Barr, R. (2000). The development of declarative memory in human infants: age-related changes in deferred imitation. Behavioral Neuroscience, 114(1), $77-83$.

Heimann, M., Laberg, K. E. \& Nordøen, B. (2006). Imitative interaction increases social interest and elicited imitation in non-verbal children with autism. Infant and Child Development, 15, 297-309.

Heimann, M., \& Meltzoff, A. N. (1996). Deferred imitation in 9- and 14-month-old infants: A longitudinal study of a Swedish sample. British Journal of Developmental Psychology, $14(1), 55-64$.

Heimann, M., \& Nilheim, K. (2004). 6-months olds and delayed actions: An early sign of an emerging explicit memory? Cognition, Brain and Behavior, VIII(3-4), 249-254.

Heimann, M., Strid, K., Smith, L., Tjus, T., Ulvund, S. E., \& Meltzoff, A. N. (2006). Exploring the relation between memory, gestural communication, and the emergence of language in infancy: A longitudinal study. Infant and Child Development, 15(3), 233-249.

Heimann, M., Ullstadius, E., Dahlgren, S.-O., \& Gillberg, C. (1992). Imitation in autism: A preliminary research note. Behavioural Neurology, 5(4), 219-227. 
Hus, V., Pickles, A., Cook, Jr., E. H., Risi, S., \& Lord, C. (2007). Using the autism diagnostic interview-revised to increase phenotypic homogeneity in genetic studies of autism. Biological Psychiatry, 61(4), 438-448.

Joseph, R. M., Tager-Flusberg, H., \& Lord, C. (2002). Cognitive profiles and socialcommunicative functioning in children with autism spectrum disorder. Journal of Child Psychology and Psychiatry 43(6), 807-820.

Kaale, A., Smith, L. \& Sponheim, E. (2012). A randomized controlled trial of preschoolbased joint attention intervention for children with autism. Journal of Child Psychology and Psychiatry, 53(1), 97-105.

Kasari, C., Sigman, M., Mundy, P., \& Yirmiya, N. (1990). Affective sharing in the context of joint attention interactions of normal, autistic, and mentally retarded children. Journal of Autism and Developmental Disorders, 20(1), 87-100.

Kaufman, A. S., \& Kaufman, N. L. (1983). Kaufman assessment battery for children. Circle Pines, MN: American Guidance Service.

Lord, C., Rutter, M., \& Le Couteur, A. (1994). Autism diagnostic interview-revised: A revised version of a diagnostic interview for caregivers of individuals with possible pervasive developmental disorders. Journal of Autism and Developmental Disorders, 24(5), 659-686.

McCarthy, D. (1972). McCarthy scales of children's abilities. New York, NY: The Psychological Corporation/Harcourt Brace Jovanovich.

Meltzoff, A. N. (1985). Immediate and deferred imitation in fourteen- and twenty-fourmonth-old infants. Child Development, 56(1), 62-72.

Meltzoff, A. N. (1988). Infant imitation and memory: nine-month-olds in immediate and deferred tests. Child Development, 59(1), 217-225. 
Meltzoff, A. N. (1995). What infant memory tells us about infantile amnesia: Long-term recall and deferred imitation. Journal of Experimental Child Psychology, 59(3), 497515.

Morales, M., Mundy, P., Delgado, C. E. F., Yale, M., Messinger, D., Neal, R., \& Schwartz, H. (2000). Responding to joint attention across the 6- through 24-month age period and early language acquisition. Journal of Applied Developmental Psychology, 21(3), 283298.

Mundy, P., Hogan, A. E., \& Doehring, P. (1996). A preliminary manual for the abridged early social communication scales (ESCS): Unpublished manuscript.

Mundy, P. Kasari, C., Sigman, M., \& Ruskin, E. (1995). Nonverbal communication and early language acquisition in children with Down syndrome and in normally developing children. Journal of Speech \& Hearing Research, 38(1), 157-167.

Mundy, P., \& Sigman, M. (2006). Joint attention, social competence and developmental psychopathology. In D. Cicchetti \& D. Cohen (Eds.), Developmental psychopathology, theory and methods (2nd ed., Vol. 1). (pp. 293-332). Hoboken, N.J.: Wiley.

Mundy, P., Sigman, M., \& Kasari, C. (1994). Joint attention, developmental level, and symtom presentation in autism. Development and Psychopathology, 6(3), 389-401.

Munson, J., Faja, S., Meltzoff, A., Abbott R., \& Dawson, G. (2008). Neurocognitive predictors of social and communicative developmental trajectories in preschoolers with autism spectrum disorders. Journal of the International Neuropsychological Society, 14, 956-966.

Nadel, J. (2002). Imitation and imitation recognition: Functional use in preverbal children with autism. In W. Prinz \& A. N. Meltzoff (Eds.), The imitative mind: Development, evolution, and brain bases (pp. 42-62). New York, NY: Cambridge University Press. 
Pry, R., Petersen, A. F., \& Baghdadli, A. (2009). Developmental changes of expressive language and interactive competences in children with autism. Research in Autism Spectrum Disorders, 3, 98-112.

Raven, J. C. (1976). Coloured progressive matrices. Oxford: Oxford Psychologists Press Ltd.

Rogers, S. J., Young, G. S., Cook, I., Giolzetti, A., \& Ozonoff, S. (2008). Deferred and immediate imitation in regressive and early onset autism. Journal of Child Psychology and Psychiatry, 49(4), 449-457.

Rose, S. A., Feldman, J. F., \& Jankowski, J. J. (2009). A cognitive approach to the development of early language. Child Development, 80(1), 134-150.

Schopler, E., Reichler, R. J., \& Renner Rochen, B. (1988). The childhood autism rating scale. Los Angeles, CA: Western Psychological Services.

Sigman, M., \& Kasari, C. (1995). Joint attention across contexts in normal and autistic children. In C. Moore \& P. J. Dunham (Eds.), Joint attention: Its origins and role in development (pp. 189-203). Hillsdale, NJ: Lawrence Erlbaum Associates.

Smith, I. M., \& Bryson, S. E. (1994). Imitation and action in autism: A critical review. Psychological Bulletin, 116(2), 259-273.

Stone, W. L., Ousley, O. Y., \& Littleford, C. D. (1997). Motor imitation in young children with autism: What's the object? Journal of Abnormal Child Psychology, 25(6), 475485.

Strid, K., Tjus, T., Smith, L., Meltzoff, A. N., \& Heimann, M. (2006). Infant recall memory and communication predicts later cognitive development. Infant Behavior and Development, 29(4), 545-553.

Tjus, T., Heimann, M. \& Nelson, K. E. (2001). Interaction patterns between children and their teachers when using a specific multimedia and communication strategy: Observations from children with autism and mixed intellectual disabilities. Autism, 5, 175-187. 
Tomasello, M. (1995). Joint attention as social cognition. In C. Moore \& P. J. Dunham (Eds.), Joint attention: Its origins and role in development (pp. 103-130). Hillsdale, NJ: Lawrence Erlbaum Associates.

Tomasello, M., \& Farrar, M. J. (1986). Joint attention and early language. Child Development, $57(6), 1454-1463$.

Toth, K., Munson, J., Meltzoff, A. N., \& Dawson, G. (2006). Early predictors of communication development in young children with autism spectrum disorder: Joint attention, imitation, and toy play. Journal of Autism and Developmental Disorders, 36(8), 993-1005.

Ulvund, S. E., \& Smith, L. (1996). The predictive validity of nonverbal communicative skills in infants with perinatal hazards. Infant Behavior and Development, 19(4), 441-449.

Wechsler, D. (1999). Wechsler pre-school and primary scale of intelligence - revised. Swedish version. Stockholm: Psykologiförlaget.

Whiten, A., \& Brown, J. D. (1998). Imitation and the reading of other minds: Perspectives from the study of autism, normal children and non-human primates. In S. Bråten (Ed.), Intersubjective communication and emotion in early ontogeny. (pp 260-280). Cambridge: Cambridge University Press.

Williams, J. H. G., Whiten, A., \& Singh, T. (2004). A systematic review of action imitation in autism spectrum disorder. Journal of Autism and Developmental Disorders, 34(3), 285-299.

Wing, L., Leekam, S. R., Libby, S. J., Gould, J., \& Larcombe, M. (2002). The diagnostic interview for social and communication disorders: background, inter-rater reliability and clinical use. Journal of Child Psychology and Psychiatry and Allied Disciplines, $43(3), 307-325$. 
Table 1

Descriptive data for the participating children both for the total groups and for the nonspeaking and speaking children with autism (expressed in months). Means (SD). Group comparisons with Mann-Whitney U test.

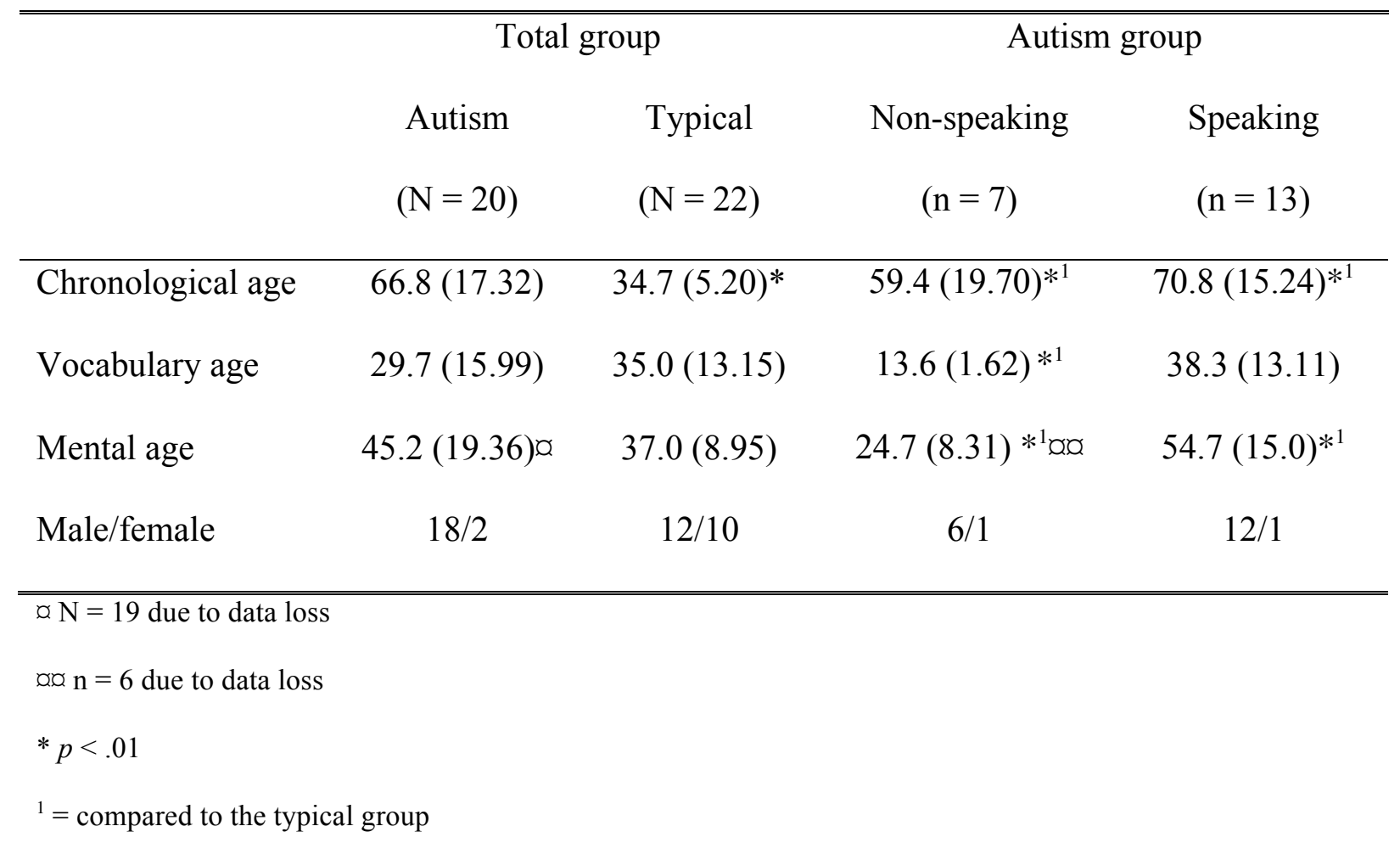


Table 2

Description of objects, target actions and scoring criteria for the objects used in the deferred imitation procedure.

\begin{tabular}{|c|c|c|c|}
\hline Object & Description & Target actions & Scoring criteria $^{1}$ \\
\hline \multicolumn{4}{|l|}{ Conventional } \\
\hline Egg & $\begin{array}{l}\text { A plastic egg with small } \\
\text { beads inside }\end{array}$ & Shaking the egg & $\begin{array}{l}\text { Moving the egg side } \\
\text { to side three times }\end{array}$ \\
\hline Collapsible cup & $\begin{array}{l}\text { A cup that collapsed when } \\
\text { pressing downward on it }\end{array}$ & $\begin{array}{l}\text { Making the cup } \\
\text { collapse by pressing } \\
\text { it }\end{array}$ & $\begin{array}{l}\text { Collapse the cup } \\
\text { more than half the } \\
\text { way }\end{array}$ \\
\hline Beads & A cup and a string of beads & $\begin{array}{l}\text { Putting the string in } \\
\text { the cup }\end{array}$ & $\begin{array}{l}\text { Putting the string in } \\
\text { the cup }\end{array}$ \\
\hline $\begin{array}{l}\text { Non- } \\
\text { conventional } \\
\text { response }\end{array}$ & & & \\
\hline Hinge & $\begin{array}{l}\text { A wooden rectangle } \\
\text { connected by a hinge to a } \\
\text { larger rectangular base }\end{array}$ & $\begin{array}{l}\text { Pushing the rectangle } \\
\text { over with the elbow, } \\
\text { so it lays flat on top } \\
\text { of the base }\end{array}$ & $\begin{array}{l}\text { Folding the vertical } \\
\text { flap down with a } \\
\text { greater arc than } 45^{\circ} \\
\text { toward the base }\end{array}$ \\
\hline Box & $\begin{array}{l}\text { A black box with a hidden } \\
\text { black button on the top, } \\
\text { which made a beeping } \\
\text { sound when pressed }\end{array}$ & $\begin{array}{l}\text { Pressing the button } \\
\text { with a pen }\end{array}$ & $\begin{array}{l}\text { Making a sound by } \\
\text { using the pen }\end{array}$ \\
\hline
\end{tabular}

\footnotetext{
${ }^{1}$ The child had to complete the target action within 20 seconds from the first time the child touched the object.
} 
Table 3

Means (SD) of correct response on deferred imitation tasks for the autism group (A) and the typical group (T) and for non-speaking (NS) and speaking (S) children with autism on deferred imitation. Group comparisons with Mann Whitney U-test.

\begin{tabular}{lccccccc}
\hline \hline & Typical (T) & Autism (A) & A(NS) & A(S) & T vs A & T vs A(NS) & T vs A(S) \\
Deferred imitation tasks & $(\mathrm{N}=22)$ & $(\mathrm{N}=20)$ & $(\mathrm{N}=7)$ & $(\mathrm{N}=13)$ & $p$ & $p$ & $p$ \\
\hline Overall (five tasks) & $3.74(.86)$ & $2.80(1.01)$ & $2.29(.95)$ & $3.08(.95)$ & $<.01$ & $<.01$ & $<.05$ \\
Conventional (3 tasks) & $2.55(.51)$ & $1.84(.69)$ & $1.58(.53)$ & $2.00(.74)$ & $<.01$ & $<.001$ & $<.05$ \\
Non-conventional (2 tasks) & $1.23(.69)$ & $.95(.51)$ & $.71(.49)$ & $1.08(.49)$ & $\mathrm{ns}$ & $\mathrm{ns}$ & $\mathrm{ns}$ \\
\hline \hline
\end{tabular}


Table 4

Means (SD) for the autism group (A) and the typical group (T) and for non-speaking (NS) and speaking (S) children with autism on nonverbal communication measures. Group comparisons with Mann-Whitney U.

\begin{tabular}{|c|c|c|c|c|c|c|c|}
\hline & $\begin{array}{c}\text { Typical (T) } \\
(\mathrm{N}=22)\end{array}$ & $\begin{array}{c}\text { Autism (A) } \\
(\mathrm{N}=20)\end{array}$ & $\begin{array}{l}\mathrm{A}(\mathrm{NS}) \\
(\mathrm{N}=7)\end{array}$ & $\begin{array}{c}\mathrm{A}(\mathrm{S}) \\
(\mathrm{N}=13)\end{array}$ & $\begin{array}{c}\text { T vs A } \\
p\end{array}$ & $\begin{array}{c}\text { T vs A(NS) } \\
p\end{array}$ & $\begin{array}{c}\mathrm{T} \text { vs A(S) } \\
p\end{array}$ \\
\hline \multicolumn{8}{|l|}{ Joint attention } \\
\hline Initiating (IJA) & $20.23(9.72)$ & $9.05(9.39)$ & $2.00(3.61)$ & $12.85(9.41)$ & $<.001$ & $<.001$ & $<.05$ \\
\hline Responding ( $R J A)$ ratio & $.96(.07)$ & $.77(.27)$ & $.43(.07)$ & $.95(.09)$ & $<.05$ & $<.001$ & ns \\
\hline \multicolumn{8}{|l|}{ Requesting } \\
\hline Initiating (IOR) & $17.14(8.34)$ & $8.80(7.22)$ & $3.43(3.96)$ & $11.69(6.99)$ & $<.01$ & $<.001$ & $<.05$ \\
\hline Responding (ROR) & $5.95(3.59)$ & $4.95(4.08)$ & $3.14(4.26)$ & $5.92(3.80)$ & ns & $<.05$ & ns \\
\hline \multicolumn{8}{|l|}{ Social Interaction } \\
\hline Initiating (ISI) & $2.32(1.25)$ & $1.15(.99)$ & $.29(.49)$ & $1.62(.87)$ & $<.01$ & $<.001$ & $\mathrm{~ns}$ \\
\hline Responding (RSI) & $13.68(7.56)$ & $8.45(8.40)$ & $1.86(2.19)$ & $12.00(8.39)$ & $<.05$ & $<.001$ & $\mathrm{~ns}$ \\
\hline
\end{tabular}

